\title{
Investigation of Cotton Germplasm for Genetic Divergence Regarding Yield Related Trait Using Principal Component Analysis
}

\section{Qudrat Ullah}

Gomal University

Muhammad Zulfiqar Ahmad ( $\nabla$ zulfiqar_nuas@yahoo.com )

South China Agricultural University

Kalim Ullah

Pakistan Central Cotton Committee, Cotton Research Station, Dera Ismail Khan

Obaidullah Sayal

Gomal University Faculty of Agriculture

Arshad Jamil

Gomal University Faculty of Agriculture

Mohammad Mohibullah

Gomal University Faculty of Agriculture

Bushra Ahmad

Shaheed Benazir Bhutto Women University

\section{Research}

Keywords: Cotton, Germplasm, Principle component analysis, Genetic diversity, Qualitative traits, Quantitative traits

Posted Date: October 23rd, 2020

DOI: https://doi.org/10.21203/rs.3.rs-94514/v1

License: (c) (i) This work is licensed under a Creative Commons Attribution 4.0 International License. Read Full License 


\section{Abstract}

Background: Cotton is a vital fiber and cash crop in Pakistan. Genetic diversity of a germplasm play an important role for cotton breeding. One hundred and two germplasm of upland cotton were investigated for genetic divergence regarding yield related attributes using principal component analysis. The research was carried out in RCB design with 2 replications. Experiment data was recorded on various qualitative and quantitative parameters and were subjected to principal components analysis (PCA) and cluster analysis.

Results: PCA result showed that only four components were considered on account of their eigenvalue greater than 1 which contributed $65 \%$ to the total variability. Score plot showed that the suncrop-6, tipu-9, TJ-max, Deebal, CRIS-543, TH20, Tahafuz-7, Eagle, BS-80, IUB-69, BH-221, NIAB-1048, and NIAB BT-2 showed the vertex of polygon and resulted as most divergent germplasm. Similarly cluster analysis also categorized the yield related traits into 5 main cluster. Cluster-1 contain 20 germplasm, cluster-II contain 16, and cluster-III, cluster-IV, and cluster-V comprise 13, 16, and 37 germplasm, respectively.

Conclusion: Based on results, it was recommended that these genetically diverse germplasm might be used as parents that could be utilized in upcoming breeding programs.

\section{Introduction}

Cotton is very important non-food cultivated and industrial fiber crop developed in more than eighty countries (Dutt et al. 2004; Shakeel et al. 2015). Due to its importance in agriculture and textile industry, therefore it is also recognized as "white gold". The Gossypium genus include 50 species so far. Amongst these 45 are diploid and five are allotetraploids. Four species are cultivated, which can be divided into two groups. First one contain (Gossypium hirsutum) and (Gossypium barbadence) $(2 n=52)$ and are cultivated from America commonly termed as new world cotton and are allotetraploids, whereas 2nd one contain (G. arboreum) and (G. herbaceum) $(2 n=26)$ and are named as ancient world cotton or Asiatic cotton, because they are cultivated mainly in Asian region (Wilkins et al. 2000).

As cotton crop is very sensitive and the performance of its cultivar varies with location as environmental conditions. Hence genetic potential and heritability of various genotype in term of performance of various morphological parameters is directly desirable for screening of high potential strain for breeding programs (Khan et al. 2010). It is obvious from the fact that development in cotton improvement programme is depending mainly on the genetic diversity in metric trait of base population (Jamil et al. 2020). Assessment of genetic variability among germplasm is of importance not for their safety \& recording but also for saving of genotypes and breeding resources (Sunseri et al. 2010). Genetic variability concentrated on several agronomic and morphological features and their relations with surrounding biotic and abiotic issues has been exploited for upcoming development in cotton breeding (Liaqat et al. 2015). The amount and nature of attainable genetic variability between the genotypes has adequate scope to develop in successful breeding program for upgrading of various attributes (Ahsan et al. 2015).

The process of principal component analysis (PCA) was working in direction to analyze the variability present in germplasm and to determine such characteristic of plant which cause the diversity to rise and to determine the comparative influences that the various characters make to the entire variability in the germplasm. PCA was working by the researchers to discover the correspondence amongst the germplasm for the characters and their appointment into various clusters. Principal component analysis also used to evaluate the relationship and variability amongst numerous germplasm for their utilization in future cotton improvement programme (Saeed et al. 2014; Rehman et al. 2015). Due to its diverse behavior of cotton for quality and quantity parameters, it is inevitable to analyze its genetics. Thus focusing this present study is being designed with defined goals mentioned as (i) to check the genetic diversity amongst different 
accession (ii) to find the magnitude of genetic diversity (iii) to evaluate and select best ones amongst different accession on morphological basis and genetic variability.

\section{Material And Method}

The field experiment was conducted using 102 accessions obtained from Cotton Research Station Dera Ismail Khan, Pakistan.

\section{Experimental layout and crop management}

One hundred and two germplasm were raised in randomized complete block design. The experiment was consists of two replications, where distance between plant to plant and row to row were $30 \& 75 \mathrm{~cm}$, respectively. Seed was sown in hills and every hill contain about 3 to 4 seeds, and the field was irrigated after sowing. About $60 \mathrm{~kg} \mathrm{ha}^{-1}$ of phosphate fertilizer as single super phosphate $\left(18 \% \mathrm{P}_{2} \mathrm{O}_{5}\right)$ and $50 \mathrm{~kg} \mathrm{ha}^{-1}$ of nitrogenous fertilizer as urea (46\%) as initial dose were applied before sowing. The remaining $50 \mathrm{~kg} \mathrm{ha}^{-1}$ of nitrogen as urea was also applied at flowering and $50 \mathrm{~kg} \mathrm{ha}{ }^{-1}$ at boll formation stage. Thinning was completed after every 20 days to make ensure single plant per hill. Picking of bolls were practiced in regular interval about 2-3 picking, and seed cotton were stored in bags. All the recommended management practices for good crop growth were carried out during experiment.

\section{Data recording and statistical analysis}

Data were recorded on various yield related traits i.e. two qualitative (boll shape and stigma position) and eleven quantitative (plant height, sympodial intermodal length, number of monopodial branches per plant, number of sympodial branches per plant, number of fruiting position per sympodia, number of node to first sympodia, plant population, bolls per plant, boll weight, seed cotton yield and ginning out turn) parameters. The data noted were subjected to statistical analysis. Descriptive statistics was performed for all the studied traits and the mean values were subjected to cluster analysis and principal component analysis was done through Minitab 18.

\section{Result}

\section{Principle component analysis (PCA)}

To explore the momentous variation among one hundred and two germplasm of upland cotton, principle component analysis was used on collected mean data of fiber quality, yield and yield related attributes simultaneously (Table 1). Out of these 11 quantitative characters, 4 principal components account for $65 \%$ of the total variability amongst the studied upland cotton germplasm for the total phenotypic variations. The first principal component (PC) among these four principal components (PCs), depicted 3.58 eigenvalue and was found to have $32.6 \%$ out of the total variability (Table 1). The first principal component (PC I) among germplasm revealed positive effect for plant height (0.165), sympodial internodal length (0.042), No. of sympodial branches plant ${ }^{-1}(0.112)$, No. of fruiting position sympodia ${ }^{-1}(0.117)$, plant population (0.435), No. of bolls plant per plant (0.486), boll weight (0.489), and seed cotton yield (0.495) (Fig. 1). Whereas in contrast No. of monopodia branches plant ${ }^{-1}(-0.029)$, number of node to first sympodia (-0.166) and ginning out turn (GOT) (-0.071) subsidized negative effect to PC I (Fig. 1; Table 1). PC II depicted 1.33 eigenvalue and contribute $12.1 \%$ to the total variability. PC II among the genotypes revealed positive effect for plant height (0.594), sympodial internodal length (0.039), No. of monopodia branches plant ${ }^{-1}(0.164)$, No. of sympodial branches plant ${ }^{-1}(0.400)$, number of node to 1 st sympodia (0.447), boll weight (0.030), seed cotton yield (0.041), and ginning out turn GOT (0.024), while number of fruiting position per sympodia (-0.499), plant population $(-0.056)$ and No. of bolls plant ${ }^{-1}(-0.034)$ showed negative result to PC II (Fig. 1; Table 1). PC III revealed 1.18 eigenvalue and contribute $10.8 \%$ to the total variability. PC III among 
germplasm revealed positive effect for plant height (0.033), No. of monopodia branches per plant (0.489), No. of fruiting position per sympodia (0.141), No. of node to first sympodia (0.124), No. of bolls per plant (0.009), boll weight (0.036) and seed cotton yield (0.072) while negative result for sympodial internodal length $(-0.655)$, No. of sympodial branches plant $^{-1}(-0.138)$, plant population (-0.088) and ginning out turn (-0.510). PC IV depicted 1.06 eigenvalue and contribute $9.7 \%$ to the total variability. The genotypes in PC IV revealed positive effect for plant height (0.135), number of fruiting position per sympodia (0.186), number of node to first sympodia (0.438), number of bolls per plant (0.085) and boll weight (0.117), seed cotton yield (0.054) and ginning out turn (0.548), while sympodial internodal length (-0.461), No. of monopodia branches plant ${ }^{-1}(-0.33)$, No. of sympodial branches plant ${ }^{-1}(-0.321)$, and plant population $(-0.027)$ exhibited negative effect (Fig. 1; Table 1).

Table 1

Principal components (PCs) of yield related traits among upland cotton genotypes.

\begin{tabular}{|c|c|c|c|c|c|c|c|c|c|c|c|}
\hline $\begin{array}{l}\text { Statistical } \\
\text { variables }\end{array}$ & PC1 & PC2 & PC3 & PC4 & PC5 & PC6 & PC7 & PC8 & PC9 & PC10 & PC11 \\
\hline Eigenvalue & 3.58 & 1.33 & 1.18 & 1.06 & 0.965 & 0.887 & 0.764 & 0.642 & 0.367 & 0.120 & 0.081 \\
\hline Proportion & 0.326 & 0.121 & 0.108 & 0.097 & 0.088 & 0.081 & 0.069 & 0.058 & 0.033 & 0.011 & 0.007 \\
\hline Cumulative & 0.326 & 0.447 & 0.555 & 0.652 & 0.74 & 0.82 & 0.89 & 0.948 & 0.982 & 0.993 & - \\
\hline PH & 0.165 & 0.594 & 0.033 & 0.135 & 0.14 & 0.163 & 0.228 & -0.67 & -0.17 & -0.085 & -0.049 \\
\hline SIL & 0.042 & 0.039 & -0.655 & -0.461 & -0.20 & 0.225 & 0.466 & 0.127 & -0.15 & 0.020 & -0.041 \\
\hline NMP & -0.029 & 0.164 & 0.489 & -0.335 & -0.585 & 0.500 & -0.148 & 0.030 & 0.046 & -0.036 & 0.019 \\
\hline NSP & 0.112 & 0.400 & -0.138 & -0.321 & -0.318 & -0.683 & -0.364 & -0.039 & -0.030 & -0.025 & 0.017 \\
\hline NFPS & 0.117 & -0.499 & 0.141 & 0.186 & -0.524 & -0.305 & 0.355 & -0.369 & -0.210 & -0.018 & -0.083 \\
\hline NDIS & -0.166 & 0.447 & 0.124 & 0.438 & -0.244 & -0.170 & 0.476 & 0.475 & 0.145 & 0.005 & -0.000 \\
\hline PP & 0.435 & -0.056 & -0.088 & -0.027 & -0.058 & 0.005 & 0.119 & -0.158 & 0.862 & 0.028 & 0.107 \\
\hline NBP & 0.486 & -0.034 & 0.009 & 0.085 & 0.028 & 0.049 & -0.038 & 0.253 & -0.171 & -0.807 & 0.062 \\
\hline BW & 0.489 & 0.030 & 0.036 & 0.117 & -0.019 & 0.060 & -0.022 & 0.147 & -0.303 & 0.470 & 0.635 \\
\hline SCY & 0.495 & 0.041 & 0.072 & 0.054 & 0.034 & 0.050 & -0.075 & 0.205 & -0.105 & 0.339 & -0.752 \\
\hline GOT & -0.071 & 0.024 & -0.510 & 0.548 & -0.388 & 0.271 & -0.44 & -0.083 & 0.026 & -0.002 & -0.038 \\
\hline \multicolumn{12}{|c|}{$\begin{array}{l}\text { PH = Plant height, SIL = Sympodial internodal length, NMP = Number of monopodia branches plant }{ }^{-1}, \mathrm{PP}=\mathrm{Plant} \\
\text { population, } \mathrm{NSP}=\text { Number of sympodia branches plant }{ }^{-1}, \mathrm{BW}=\text { Boll weight, NFPS }=\text { Number of fruiting position } \\
\text { sympodia }{ }^{-1}, \mathrm{NBP}=\text { Number of bolls plant }{ }^{-1}, \mathrm{NDIS}=\text { Number of node to first sympodia, } \mathbf{S C Y}=\text { Seed cotton yield, GOT } \\
=\text { Ginning out turn }\end{array}$} \\
\hline
\end{tabular}

\section{Score plot}

The score plot also called as polygon produced in principal components analysis differentiated one hundred and two (102) germplasm based on their genetic pattern. The following germplasm are present at the vertex of polygon and resulted as most divergent germplasm. These germplasm are suncrop-6, tipu-9, TJ-max, Deebal, CRIS-543, TH-20, Tahafuz-7, Eagle, BS-80, IUB-69, BH-221, NIAB-1048, and NIAB BT-2 (Fig. 2). In contrast, some germplasm were present near to the origin of polygon in which minimum genetic divergence present due to their narrow genetic bases and supposed as being genetically similar. Criss-600, BH-201, MPS-29, Cyto-225, crystal-12, Bahar-07, FH-444, GS-Ali were 
found closer to the origin of polygon, hence presented less genetic diversity and breeding importance for future breeding programs.

The most frequently used criteria in principal component analysis for finding principle components is the eigenvalue-one criterion, also called as the Kaiser criterion (Kaiser 1960). By using this method, we conserve and analyze any component with an eigenvalue $>1$. Out of eleven (11) principle components, four principle components were represented eigenvalue $>$ 1 and cumulative variability of $65 \%$ for all the traits. The PC I and PC II subsidizes about $44.7 \%$ of cumulative variability. The parameters of significance were sympodial internodal length, number of sympodial branches plant ${ }^{-1}$, plant height, boll weight, seed cotton yield depicted in PC I and PC II expressed great contribution towards cumulative variability. These attributes should have granted special importance for cotton improvement in future breeding program. Previous findings of these attributes depicting their contribution towards cumulative variability and future cotton improvement programs were also stated by (Saeed et al. 2014; Kaleri et al. 2015; Latif et al. 2015; Jamil et al. 2020).

Suncrop-6, tipu-9, TJ-max, Deebal, tahaffuz, BS-80, IUB-69, BH-221, NIAB-1048, NIAB BT-2 were most genetically diverse germplasm. These germplasm could be utilized in future development program to extend the genetic base through various breeding programs. The score plot scattered the germplasm based on the existence of significant genetic variation (Liaqat et al. 2015; Jamil et al. 2020). The distance from the origin of plot and germplasm showed the level of genetic divergence of germplasm i.e., if the distance between germplasm and origin is greater than it show greater significance diversity among germplasm and vice versa (Rana et al. 2013).

\section{Cluster analysis}

One hundred and two germplasm were categorized into 5 clusters based on several yield related traits (Table 2). Clustering pattern of germplasm under this research work reveals that the germplasm indicated significant genetic diversity amongst themselves by classifying into 5 diverse clusters (Table 2). A Euclidean distance based dendogram was constructed to separated 102 germplasm into 5 main clusters (Fig. 3). Among all the upland cotton germplasm, a high of Euclidean distance was observed. Cluster-I, contain twenty germplasm, and this cluster was further sub divided into 3 cluster i.e. sub cluster I, sub cluster II, and sub cluster III comprised 4, 8, and 8 germplasm respectively (Fig. 3). Cluster-II also contain sixteen germplasm which further sub divided into 2 main sub cluster i.e. sub cluster I and sub cluster II containing 8 and 8 germplasm respectively (Fig. 3). In the cluster-III, thirteen germplasm of upland cotton were grouped and this cluster was further subdivided into two main sub clusters, i.e. sub cluster I and II, comprised 5 and 8 germplasm respectively (Fig. 3). Similarly cluster IV containing maximum 37 germplasm which are further more sub divided into five main cluster, i.e. sub cluster I, sub cluster II, sub cluster III, sub cluster IV, and sub cluster V comprise 7, 8, 10,8 , and 4 germplasm respectively followed by Cluster-V, which consist of 16 individuals and further sub divided into two sub groups, sub cluster I and sub cluster II, containing 10 and 6 germplasm, respectively (Fig. 3). 
Table 2

Clustering pattern of all 102 germplasm upland cotton through cluster analysis based on yield related traits.

\begin{tabular}{|c|c|c|c|}
\hline Clusters & $\begin{array}{l}\text { No. of } \\
\text { Accession }\end{array}$ & Percentage & Germplasm \\
\hline Cluster-I & 20 & $1.96 \%$ & $\begin{array}{l}\text { GS.Ali-5, BS-15, MNH-1026, RH 622, CIM-602, Tipu-1, Sahara-210, CIM-663, } \\
\text { KZ-125, VH-383, BZU-05, IUB-69, Tassco-209, SLH-6, SLH-19, Shaheen-16, GS } \\
\text { ali-7, CRIS-600, MPS-61, TH-20 }\end{array}$ \\
\hline Cluster- & 16 & $9.58 \%$ & $\begin{array}{l}\text { BH-221, FH-142, ICI-2121, CIM-632, Tahaffuz-10, BPC-11, RH-Afnan, MPS-29, } \\
\text { Sitara-16, TJ-Max, NIA-85, Sasul-2018, CIM-777, GS-Hammad, SLH-6, BS-80. }\end{array}$ \\
\hline $\begin{array}{l}\text { Cluster- } \\
\text { III }\end{array}$ & 13 & $7.78 \%$ & $\begin{array}{l}\text { CEMB-88, MNH-1016, Tahaffuz-7, CEMB-101, CEMB-88, NIAB-1048, NIA-85, } \\
\text { KZ-125, RH-622, BH-221, NIA-85, CIM-343, CYTO-225 }\end{array}$ \\
\hline $\begin{array}{l}\text { Cluster- } \\
\text { IV }\end{array}$ & 37 & $22.1 \%$ & $\begin{array}{l}\text { BS-15, FH-152, RH-667, GS-Ali-7, Eagle, GS-ALI-5, CIM-777, VH-189, CIM610, } \\
\text { Sitara-16, SLH-6, CYTO-225, NIAB-1048, RH-667, CEMB-55, CYTO-313, FH-142, } \\
\text { Taizan-5, CEMB-100, BPC-11, CIM-663, GS-ALI-5, Eryol-1148, Tassco-209, } \\
\text { Thakkar-808, BPC-11, VH-383, CEEMB-88, RH-Manther, CIM-602, CEMB-55, } \\
\text { NIAB-1048, TJ-17, FH-444, NS-191, Suncrop-6, Sikandar-1. }\end{array}$ \\
\hline Cluster- & 16 & $9.58 \%$ & $\begin{array}{l}\text { MNH-1016, CEMB-88, RH-622, MNH-1016, AA-993, IUB-60, CRIS-600, BPC-10, } \\
\text { GH-HADDI, ICl-2121, Deebal, Tahaffuz-7, CRIS-613, BH-221, Shahab-7, DNH- } \\
1105\end{array}$ \\
\hline
\end{tabular}

In current research it was perceived that the characters table in the cluster-I had highest plant height (145 cm), maximum No. of sympodial branches plant ${ }^{-1}$ (31.4) however minimum number of bolls plant ${ }^{-1}$ (73.8) and ginning out turn (GOT) (37.6) were observed in cluster I. The germplasm comprising cluster II for maximum number of fruiting position per sympodia (5.92), taking maximum boll weight (2.36), and maximum seed cotton yield (1523.07) while in cluster II minimum number of monopodia branches plant ${ }^{-1}$ (3.38) and sympodial internodal length (6.06) were observed. The accessions containing cluster-III were detected for maximum number of monopodia branches per plant (3.69), maximum number of node to first sympodia (5.69) and also comprise maximum number of bolls per plant (81.23), while those character which contain minimum number were not found in cluster III (Table 3). The germplasm comprising cluster IV were categorized for maximum sympodial internodal length (7.93), maximum number of plant population (38.91) and also comprise maximum ginning out turn (38.2) while lower plant height (132.3), minimum number of sympodial branches per plant (29.5) were observed in cluster IV. The last major cluster-V comprised of 16 accessions and observed for minimum plant population (33), boll weight (2.20) and seed cotton yield (1200) (Table 3). 
Table 3

Mean and standard deviation (SD) of five clusters.

\begin{tabular}{|c|c|c|c|c|c|}
\hline Traits & Cluster-I & Cluster-II & Cluster-III & Cluster-IV & Cluster-V \\
\hline Plant height & $145 \pm 23.08$ & $135.2 \pm 21.85$ & $144.7 \pm 21.08$ & $\begin{array}{l}132.3 \pm \\
20.2\end{array}$ & $\begin{array}{l}140.9 \pm \\
18.8\end{array}$ \\
\hline Sympodial internodal length & $7.5 \pm 2.4$ & $6.06 \pm 2.5$ & $7.12 \pm 2.3$ & $7.93 \pm 2.4$ & $7.1 \pm 28.6$ \\
\hline $\begin{array}{l}\text { Number of monopodial branches } \\
\text { plant }^{-1}\end{array}$ & $3.4 \pm 1.01$ & $3.38 \pm 1.04$ & $3.69 \pm 0.94$ & $3.47 \pm 1.05$ & $3.56 \pm 2.8$ \\
\hline $\begin{array}{l}\text { Number of sympodial branches } \\
\text { plant }^{-1}\end{array}$ & $31.4 \pm 5.3$ & $30.07 \pm 5.7$ & $30.38 \pm 6.03$ & $29.5 \pm 5.1$ & $31.37 \pm 2.7$ \\
\hline $\begin{array}{l}\text { Number of fruiting position } \\
\text { sympodia }^{-1}\end{array}$ & $4.8 \pm 2.00$ & $5.92 \pm 2.00$ & $5.07 \pm 2.1$ & $5.6 \pm 1.53$ & $5.87 \pm 5.7$ \\
\hline Number of node to first sympodia & $5.10 \pm 1.3$ & $5.46 \pm 1.12$ & $5.69 \pm 1.1$ & $5.22 \pm 0.92$ & $5.47 \pm 2.1$ \\
\hline Plant population & $38.6 \pm 14.3$ & $36.5 \pm 13.5$ & $34.3 \pm 11.8$ & $38.91 \pm 9.5$ & $33 \pm 0.4$ \\
\hline Bolls plant ${ }^{-1}$ & $73.8 \pm 12.00$ & $80 \pm 18.04$ & $81.23 \pm 14.4$ & $74.4 \pm 12.4$ & $74.75 \pm 3.0$ \\
\hline Boll weight & $2.29 \pm 0.41$ & $2.36 \pm 0.49$ & $2.35 \pm 0.33$ & $2.27 \pm 0.42$ & $2.20 \pm 3.4$ \\
\hline Seed cotton yield & $\begin{array}{l}1400.0 \pm \\
0642.6\end{array}$ & $\begin{array}{l}1523.07 \pm \\
528.4\end{array}$ & $\begin{array}{l}1423.07 \pm \\
516.06\end{array}$ & $\begin{array}{l}1300 \pm \\
483.4\end{array}$ & $\begin{array}{l}1200 \pm \\
632.8\end{array}$ \\
\hline Ginning out turn (GOT) & $37.6 \pm 2.01$ & $37.7 \pm 1.84$ & $37.6 \pm 2.02$ & $38.2 \pm 2.1$ & $37.6 \pm 1.83$ \\
\hline
\end{tabular}

\section{Discussion}

Classification of crop is pre-requisite for protection of plant genetic resources and gene banks management. This evidence is useful to monitor large population of plant resources for desirable traits and useful to recognize superior genotypes i.e. high yielding, early maturing, resistant to biotic and a biotic stresses and eco-friendly. Similarly, the same evidence can be used by plant breeders as an example in crop improvement programs (Ghafoor 1999). The exploitation of several biometrical techniques comprising PCA and cluster analysis for germplasm classification into dissimilar clusters created on their performance for yield related traits have been stated in earlier studies (Qiaoling and Zhe 2011). Assessment and characterization by yield relating traits of diverse crop species is therefore highly significant for plant breeders (Martins et al. 2006). It is therefore essential to estimate the genetic differences of the plant genotypes and examine each and every characteristic of it and preserve it for using in the future breeding programs. The valuation of overall genetic divergence present in a crop germplasm also helps to calculate magnitude of genetic load and stress being faced by population which aids experts to devise conservational strategies in advance for the species threatened. Therefore, the objectives of the present investigation included morphological as well biochemical characterization of previously 102 germplasm of upland cotton from diverse eco-geographical background. Population was screened for 2 Qualitative and 11 quantitative yield-morphological traits to measure genetic divergence present in the germplasm.

\section{Principal Component Analysis based on yield related traits}

Upland cotton germplasm were examined through PCA and then made groups on the basis of resemblances detected in morphological traits of these characters detached from their origination from the similar or diverse ecological zones. PCA is frequently used in crop sciences for the falling of variables and to categorize the germplasm. Biometrical processes amongst these concluded that the key benefit of PCA is that every germplasm can be allotted to simply one group and it 
also replicates the significance of the principal contributor to the overall variability at each axis of differentiation (Sharma 2006). Genetic diversity for yield related traits has been assessed by principal component analysis, which clues to and identify variability in upland cotton ( $\mathrm{Li}$ et al. 2008). Many researchers stated that prevailing diversity in colored cotton genotypes may offer wide scope in field of colored cotton classification (Ashokkumar and Ravikesavan 2011; Malik et al. 2011). PC well-defined as a reduced data form, which make clear the relationship between breeding materials into interpretable less dimensions to produce new variables. PCA first determines Eigen values, which describe the quantity of total variation exhibited on the component axes. PCA and Cluster analysis might be used mutually to describe diversity in breeding constituents in genetic diversity studies. The principal component analysis distributes the entire variance into dissimilar factors. Principal component decreases the dimension of multivariate data by removing interrelations between variables and Eigen value characterizes the variance of principal component (Matus et al. 1999). The number of common aspects to be reserved must be equal to the number of PCs having Eigen values more than 1 (Kaiser 1960). This indicates that every component that shows an Eigen value larger than 1.00 is accounting for a greater quantity of variance than had been subsidized by one variable. Therefore, such a component is measured accounting for a significant amount of variance. Besides this, a component which have Eigen value smaller than 1.00 is accounting for a smaller amount of variance than had been added by one variable. The grouping of germplasm into different clusters demonstrated the occurrence of genetic variability in these individuals. Even though the scattered diagram of PCA for these germplasm denoted significant level of diversity in these studied individuals, which can be more utilized for varietal improvement and future breeding development programs. From current analysis it was observed that these grouping pattern were not due to the assortment and origination of genotypes from the similar environment, because some germplasm have similar origin but have different groups. From the present investigation of upland cotton germplasm noticeable level of diversity amongst the germplasm for diverse yield related traits was perceived and these germplasm can be exploited for further breeding progress programs. The score plot made by PC denoted that variables are great fully imposed as vector. From center, the size or distance of vector explains the comparative variability contribution made by each variable. The genotypes which fall away from the origin are considered more diverse and vice versa. Such result were also concluded by (Saeed et al. 2014), who observed primary role of PC1 and PC2 for diversity calculation of dissimilar germplasm.

\section{Cluster Analysis based on yield and morphological traits}

Numerous plant breeders and plant scientist in the earlier era had practiced and got remarkable results of diversity in yield morphological parameters for various cotton individuals through two complementary methods i.e. cluster analysis and PCA. These techniques were successfully observed in cotton. All the above mentioned plant breeders and plant scientist's results gives support to our present investigation that these 2 techniques are very supportive in estimated associations among individuals originated from different environments in a more clear approach.

The classification of present studied upland cotton germplasm into various groups was not due to of its origination from diverse ecological zones of the country and world. But their classification was because of their diversity at agronomic and morphological levels. The qualitative and quantitative traits of Iberian pea genotypes were also in agreement with our results (Amurrio et al. 1995).

\section{Conclusion}

The estimates of genetic diversity were examined through PCA and cluster analysis which revealed that out of the eleven principle components, four components were depicted eigenvalue $>1$ and cumulative variability of $65 \%$ for all the studied attributes. The PC I and PC II contribute about $44.7 \%$ of cumulative variability. Suncrop-6, tipu-9, Tj-max, Deebal were found as most genetically diverse germplasm. These most diverse germplasm could be utilized in future cotton improvement program.

\section{Declarations}




\section{Ethics approval and consent to participate}

Not applicable.

\section{Consent for publication}

All co-authors has consent for submission of manuscript.

\section{Availability of data and material}

No other data related to this study is available at this time.

\section{Competing interests}

The authors declare that there is no competing interests.

\section{Funding}

No funding source

\section{Authors' contributions}

Obaidullah Sayal and Kalim Ullah Design the study. Qudrat Ullah has conducted the experiment. Qudrat Ullah and Arshad Jamil generated the data. Muhammad Zulfiqar Ahmad analysed the data. Qudrat Ullah and Muhammad Zulfiqar Ahmad wrote the manuscript. Mohammad Mohibullah and Bushra Ahmad critically reviewed the manuscript. All authors read and approved the final manuscript and have made substantive intellectual contributions to the manuscript.

\section{Acknowledgements}

Pakistan Central Cotton Committee, Cotton Research Station, Ratta Kulachi, Dera Ismail Khan, Pakistan for providing all research inputs and bearing the cost of field experiment.

\section{References}

1. Ahsan MZ, Majidano MS, Bhutto H, Soomro AW, Panhwar FH, Channa AR, Sial KB. Genetic variability, coefficient of variance, heritability and genetic advance of some Gossypium hirsutum L. accessions. Journal of Agricultural Science. 2015;7(2):147.

2. Amurrio JM, De Ron A, Zeven A. Numerical taxonomy of Iberian pea landraces based on quantitative and qualitative characters. Euphytica. 1995;82(3):195-205.

3. Ashokkumar K, Ravikesavan R. Morphological diversity and per se performance in upland cotton (Gossypium hirsutum L.). Journal of Agricultural Science. 2011;3(2):107.

4. Dutt Y, Wang X, Zhu Y, Li Y. Breeding for high yield and fibre quality in coloured cotton. Plant Breeding. 2004;123(2):145-151.

5. Ghafoor A (1999). Genetic diversity and gene-action in Vigna mungo based on morphological and biochemical markers, Quaid-i-Azam University Islamabad, Pakistan.

6. Jamil A, Khan SJ, Ullah K. Genetic diversity for cell membrane thermostability, yield and quality attributes in cotton (Gossypium hirsutum L.). Genetic Resources and Crop Evolution. 2020;1-10.

7. Kaiser HF. The application of electronic computers to factor analysis. Educational and psychological measurement. 1960;20(1):141-151. 
8. Kaleri A, Rajput S, Kaleri G, Kaleri M, Marri J. Analysis of Genetic diversity in genetically modified and non-modified cotton (Gossypium hirsutum L.) genotypes. Journal of Agriculture and Veterinary Sciences. 2015;8(12):70-76.

9. Khan Al, Awan FS, Sadia B, Rana RM, Khan IA. Genetic diversity studies among coloured cotton genotypes by using RAPD markers. Pakistan Journal of Botany. 2010;42(1):71-77.

10. Latif A, Bilal M, Hussain SB, Ahmad F. Estimation of genetic divergence, association, direct and indirect effects of yield with other attributes in cotton (Gossypium hirsutum L.) using biplot correlation and path coefficient analysis. Tropical Plant Research. 2015;2(2):120-126.

11. Li Z, Wang X, Zhang Y, Zhang G, Wu L, Chi J, Ma Z. Assessment of genetic diversity in glandless cotton germplasm resources by using agronomic traits and molecular markers. Frontiers of Agriculture in China. 2008;2(3):245-252.

12. Liaqat S, Ahmed RI, Ahmad S, Bilal M, Karim A, Qayyum A, Ahmed R, Rafiq M. Evaluation of diverse germplasm of cotton (Gossypium hirsutum L.) for yield and fiber attributes by multivariate analysis approach. Basic Research Journal of Agricultural Science and Review. 2015;4(5):146-150.

13. Malik W, Iqbal MZ, Khan AA, Noor E, Qayyum A, Hanif M. Genetic basis of variation for seedling traits in Gossypium hirsutum L. African Journal of Biotechnology. 2011;10(7):1099-1105.

14. Martins S, Vences F, de Miera LS, Barroso M, Carnide V. RAPD analysis of genetic diversity among and within Portuguese landraces of common white bean (Phaseolus vulgaris L.). Scientia Horticulturae. 2006;108(2):133-142.

15. Matus I, González MI, Del Pozo A. Evaluation of phenotypic variation in a Chilean collection of garlic (Allium sativum L.) clones using multivariate analysis. Plant Genetic Resources Newsletter. 1999;117(31-36.

16. Qiaoling W, Zhe L. Principal component analysis of F2 individual selection in upland cotton (Gossypium hirsutum L.). Journal of Henan Institute of Science and Technology. 2011;5(4.

17. Rana RM, Rehman SU, Ahmed J, Bilal M. A comprehensive overview of recent advances in drought stress tolerance research in wheat (Triticum aestivum L.). Asian Journal of Agriculture and Biology. 2013;1(29-37.

18. Rehman SU, Abid MA, Bilal M, Ashraf J, Liaqat S, Ahmed RI, Qanmber G. Genotype by trait analysis and estimates of heritability of wheat (Triticum aestivum L.) under drought and control conditions. Basic Research Journal of Agricultural Science and Review. 2015;4(4):127-134.

19. Saeed F, Farooq J, Mahmood A, Riaz M, Hussain T, Majeed A. Assessment of genetic diversity for Cotton leaf curl virus (CLCUD), fiber quality and some morphological traits using different statistical procedures in' Gossypium hirsutum'L. Australian Journal of Crop Science. 2014;8(3):442.

20. Shakeel A, Talib I, Rashid M, Saeed A, Ziaf K, Saleem MF. Genetic diversity among upland cotton genotypes for quality and yield related traits. Pakistan Journal of Agricultural Sciences. 2015;52(73-77.

21. Sharma JR (2006). Statistical and biometrical techniques in plant breeding, New Age International.

22. Sunseri F, Polignano G, Alba V, Lotti C, Bisignano V, Mennella G, et al. Genetic diversity and characterization of African eggplant germplasm collection. African Journal of Plant Science. 2010;4(7):231-241.

23. Wilkins TA, Rajasekaran K, Anderson DM. Cotton biotechnology. Critical Reviews in Plant Sciences. 2000;19(6):511550 .

\section{Figures}




\section{Scree Plot of PH, ..., GOT}

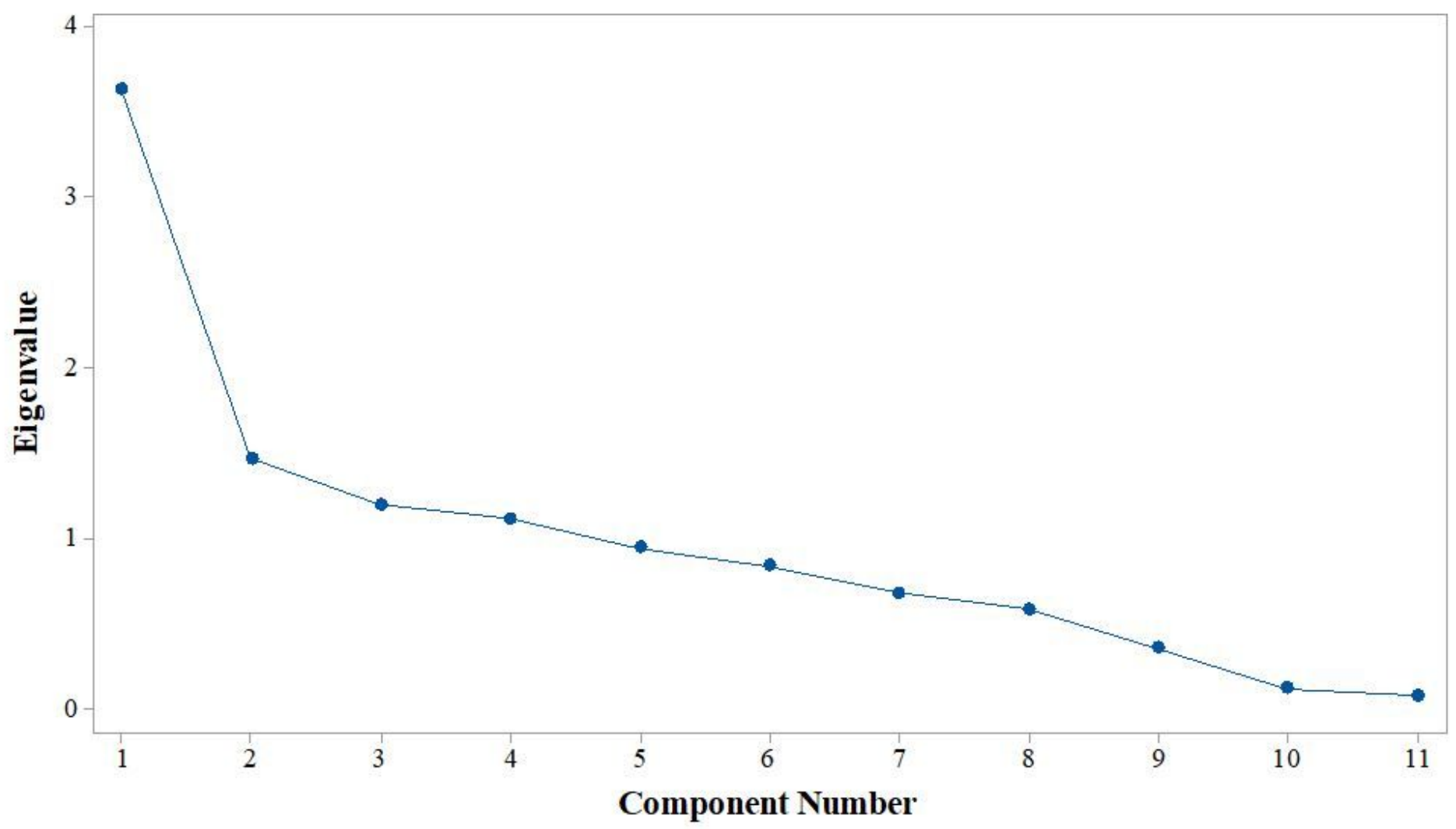

Figure 1

Scree plot showing the eigenvalue of different principle components on the basis of studied parameters 


\section{Score Plot of PH, ..., GOT}

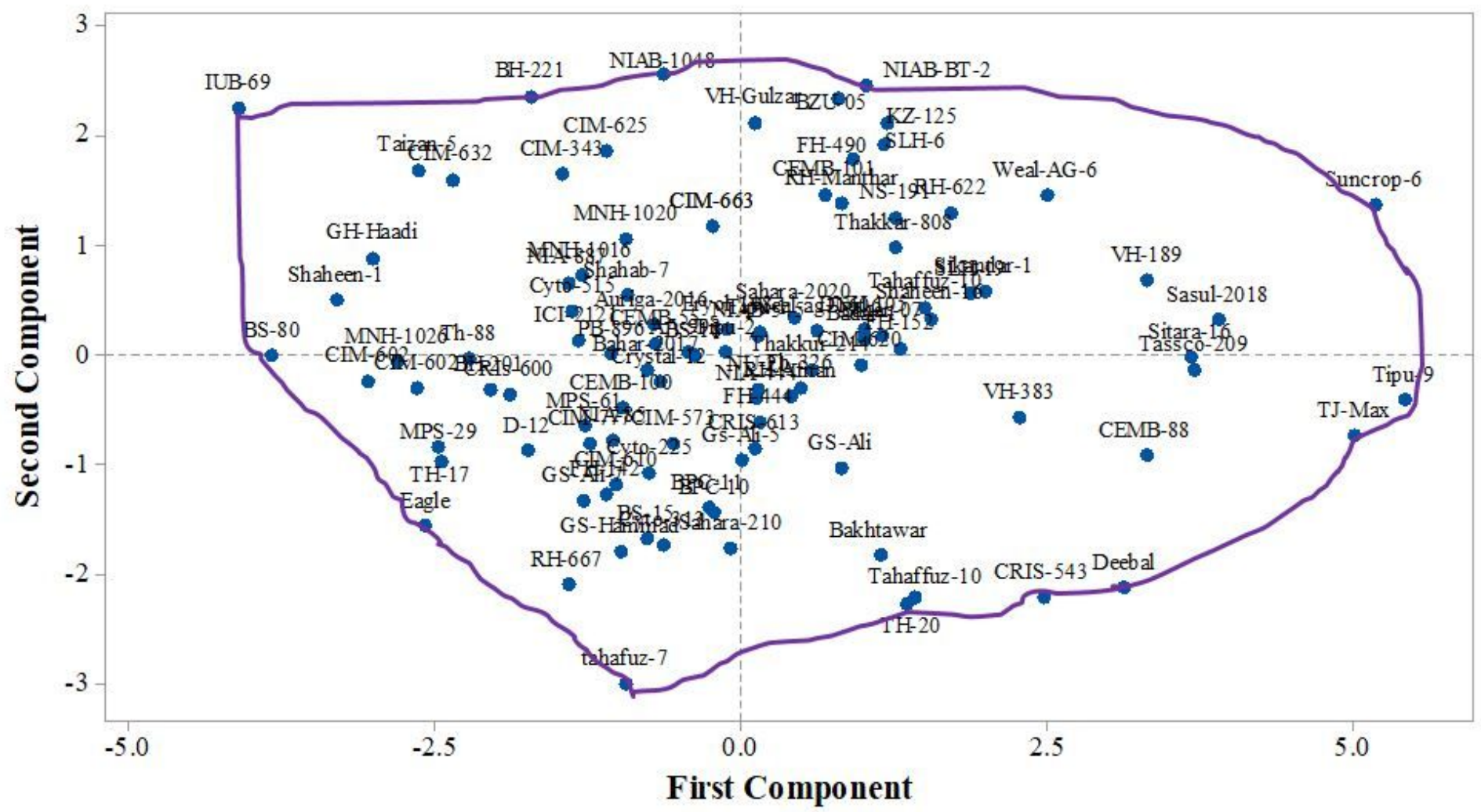

Figure 2

Score plot showing the eigenvalue of different principle components on the basis of studied parameters

\section{Dend rogram}

Complete Linkage, Correlation Coefficient Distance

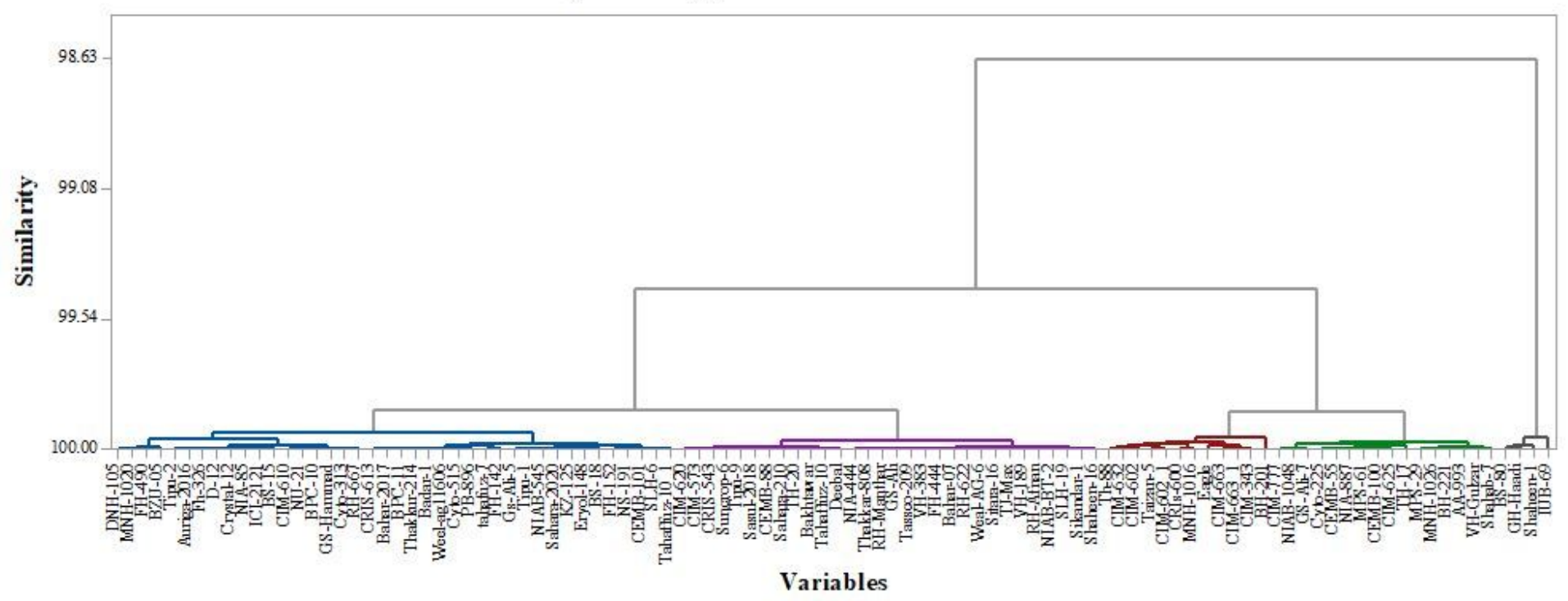

Figure 3

Dendrogram distributing 102 cotton germplasm into five clusters 